\title{
Opioid and Substance Use Disorder and Receipt of Treatment Among Parents Living With Children in the United States, 2015-2017
}

Lisa Clemans-Cope, $\mathrm{PbD}$

Victoria Lynch, MS

Marni Epstein, BA

Genevieve M. Kenney, MA, PbD

Urban Institute, Washington, DC
Conflicts of interest: authors report none.

\section{CORRESPONDING AUTHOR}

Lisa Clemans-Cope

Urban Institute

2100 M Street NW

Washington, DC 20037

lclemans@urban.org

\begin{abstract}
PURPOSE Little is known about the prevalence of opioid use disorder (OUD) among parents who are living with children and their receipt of treatment, which could reduce the harmful effects of OUD on families.
\end{abstract}

METHODS We used 2015-2017 cross-sectional national survey data to estimate prevalence and treatment of opioid use disorder and other substance use disorders (SUD) among parents living with children.

RESULTS An estimated 623,000 parents with opioid use disorder are living with children, and less than one-third of these parents received treatment for illicit drug or alcohol use at a specialty facility or doctor's office. Treatment rates were even lower among the more than 4,000,000 parents estimated to have other SUDs.

CONCLUSION Many parents in both groups have concurrent mental health issues, including suicidal thoughts and behavior. Primary care practices can play a critical role in screening and facilitating treatment initiation.

Ann Fam Med 2019;17:207-211. https://doi.org/10.1370/afm.2389.

\section{INTRODUCTION}

T

The rate of opioid use disorder (OUD) in the United States has increased over the past 2 decades. ${ }^{1}$ Children whose parents have OUD are at higher risk of experiencing health and emotional problems, cognitive deficits, and family instability. ${ }^{2 \cdot 6}$ Research shows about 1 in 5 people with OUD receive treatment, ${ }^{7}$ but little is known about the prevalence of OUD among parents who are living with children and their receipt of treatment, which could reduce the harmful effects of OUD on families. A previous report using data from 2009 to 2014 studied characteristics of children living in a household with a parent who had a substance use disorder (SUD) ${ }^{8}$; that study is dated, however, and did not examine parental OUD or treatment. We used new data from the same source to fill this research gap.

\section{METHODS}

We used the 2015-2017 National Survey of Drug Use and Health (NSDUH), a nationally representative cross-sectional survey drawn from a state-based multistage probability sample of people aged $\geq 12$ years (annual sample size $>65,000$ ), conducted by the Substance Abuse and Mental Health Services Administration. ${ }^{9}$ The data were collected via computerassisted self-interview for privacy; nonetheless, SUD prevalence, particularly for OUD, was likely underestimated because of social desirability bias and other factors..$^{10}$ Our sample of interest was defined as any parent living with a child aged $<18$ years. Opioid use disorder was defined as meeting criteria in the Diagnostic and Statistical Manual of Mental Disorders, 4th edition (DSM-IV), which relates to past-year use of heroin or prescription 
pain relievers." Other SUDs were defined as meeting criteria in the DSM-IV.

To provide context for estimates of parental OUD and treatment rates, we calculated the prevalence of (1) OUD (with or without a co-occurring SUD) and (2) $\geq 1$ SUDs without co-occurring OUD among parents in households with children aged $<18$ years and compared the 2 groups. We calculated the rates of treatment for use of illicit drugs, alcohol, and mental health among those in each group, focusing on settings associated with more intensive treatment such as specialty facilities (eg, hospital inpatient, rehabilitation inpatient, rehabilitation outpatient clinic, outpatient mental health center) or other doctor's office (eg, office-based buprenorphine treatment for OUD) and excluding services at an emergency department, self-help group, or jail or prison setting. We used recommended survey weights and standard errors. We calculated $95 \%$ CIs for all estimates and adopted 2-tailed $t$ test with $P<.05$ as the threshold for statistical significance. The analysis was conducted in Stata version 15 (StataCorp, LLC) and was exempted by the Urban Institute's Institutional Review Board.

\section{RESULTS}

We identified 44,464 parents living in households with children in the 2015-2017 sample, 446 of whom had OUD and 2,955 had $\geq 1$ SUDs but not OUD (Table 1). The rate of OUD among parents was $0.9 \%(95 \% \mathrm{CI}$, 0.8-1.0), which implies that an estimated 623,000 parents with an OUD are living with a child aged $<18$ years (95\% CI, 548,000-698,000; data not shown). Of these, $42.2 \%$ (95\% CI, 35.5-48.8) had OUD and $\geq 1$ other SUD. Among parents living in households with children, 5.9\% (95\% CI, 5.6-6.1), or an estimated 4.206 million parents (95\% CI, 4.022-4.391 million, data not shown), were identified as having SUDs but not OUD. The parents with OUD were lower income, more likely to be non-Hispanic white, and more likely to have Medicaid compared with those with SUDs but not OUD. More than 1 in 5 parents with OUD had suicidal thoughts and behavior, and nearly one-fourth had serious mental illness, indicating higher rates of mental health problems compared with parents with SUDs other than OUD. In 2015-2017, 28.0\% of the parents with OUD received treatment for illicit drug or alcohol use at a specialty facility or other doctor's office, compared with $5.6 \%$ of the group with SUDs but not OUD (Table 2), a difference of 22.4 percentage points (95\% CI, 15.9-28.8, $P<.05$, data not shown). The rate of receipt of treatment for alcohol use at a specialty facility or other doctor's office was 5.9\% among parents with OUD (95\% CI, 3.4-8.5) and was similarly low for parents with SUDs other than OUD, despite the substantial prevalence of alcohol use disorder in both groups, at $22.4 \%$ (95\% CI, 17.3-27.6) and $85.7 \%(95 \% \mathrm{CI}, 83.9-87.6)$, respectively. Among parents with OUD, $42.2 \%$ received any mental health treatment, compared with $26.0 \%$ for those with SUDs but not OUD, a difference of 16.2 percentage points (95\% CI, 8.8-23.5; $P<.05$, data not shown).

\section{DISCUSSION}

We found that more than half a million parents with OUD are living with children. Less than one-third of these parents reported that they had received treatment for illicit drug or alcohol use, and about two-fifths received mental health treatment. Among the $>4$ million parents with SUD but not OUD, less than one-tenth received treatment for illicit drugs or alcohol, and about one-fourth received mental health treatment.

Low receipt of substance use treatment among parents with OUD and other SUDs may be related to low rates of SUD identification and diagnosis by providers, low rates of treatment initiation after diagnosis, or both. The US Preventive Services Task Force recommends screening for unhealthy alcohol use among adult patients in primary care settings and providing brief behavioral counseling interventions to reduce unhealthy alcohol use when appropriate. ${ }^{12}$ Routine screening and brief intervention for illicit drug use are recommended as a preventive service in primary care by the US Surgeon General ${ }^{13}$ and federal health agencies. ${ }^{14,15}$ Primary care providers are well positioned to provide routine screening of substance use among parents because primary care visits are the most common type of health care utilization among parents. ${ }^{16}$ Moreover, primary care providers with sufficient support and clinical staff could help address unmet mental health needs among these parents through screening and facilitated referral. The US Preventive Services Task Force recommends screening for depression among adult patients in primary care settings, ${ }^{17}$ which may be particularly important for those with OUD, because of the reported high prevalence rates of co-occurring mental health conditions.

An area for further study is whether screening parents for SUDs and mental health conditions at pediatric care practices could inform treatment decisions for pediatric patients and facilitate referrals to evidence-based care for parents. This is a critical knowledge gap because many studies demonstrate an association between adverse experiences in childhood, such as parental SUDs, and health problems later in life, including mental health problems and SUDs. ${ }^{6,18,19}$ 
Primary care practices can play a number of important roles in addressing SUD issues among parents, including screening for SUDs, diagnosing, motivating change in substance use behaviors when appropriate (eg, by initiating a brief counseling intervention or brief treatment with motivational interviewing or cognitive-behavioral therapy and information about medication-assisted treatment $[\mathrm{MAT}]^{20}$ ), engaging patients in treatment decision making, ${ }_{1}^{21}$ and developing a plan for follow-up either in the primary care setting or with a specialty provider. ${ }^{22}$ In the context of patient-centered, comprehensive care, MATs such

Table 1. Sociodemographic and Health Characteristics of Parents Living With Their Children ${ }^{\mathrm{a}}$ by Past 12 Months OUD or Other SUD Status, ${ }^{b}$ 2015-2017

\begin{tabular}{|c|c|c|c|c|c|}
\hline & \multicolumn{2}{|r|}{ OUD } & \multirow{2}{*}{$\begin{array}{l}\text { P Value for } \\
\text { Difference }^{c}\end{array}$} & \multicolumn{2}{|c|}{ SUDs Except OUD [Ref] } \\
\hline & $\mathrm{n}$ & $\%(95 \% \mathrm{Cl})$ & & n & $\%(95 \% \mathrm{Cl})$ \\
\hline \multicolumn{6}{|l|}{ Age group, y } \\
\hline$\leq 25$ & 103 & $11.0(7.8,14.1)$ & 0.59 & 652 & $10.0(8.8,11.2)$ \\
\hline $26-34$ & 171 & $35.4(28.6,42.1)$ & 0.31 & 1,001 & $31.5(28.8,34.1)$ \\
\hline$\geq 35$ & 172 & $53.7(46.3,61.0)$ & 0.20 & 1,302 & $58.5(56.0,61.0)$ \\
\hline Female sex & 251 & $48.9(42.8,54.9)$ & 0.04 & 1,408 & $42.6(40.0,45.3)$ \\
\hline \multicolumn{6}{|l|}{ Family income as a \% of the federal poverty leveld } \\
\hline$<100$ & 162 & $29.0(23.2,34.7)$ & 0.00 & 719 & $19.4(17.3,21.4)$ \\
\hline $100-200$ & 135 & $28.6(22.4,34.8)$ & 0.11 & 752 & $22.9(20.7,25.1)$ \\
\hline$>200$ & 149 & $42.5(34.3,50.7)$ & 0.00 & 1,484 & $57.7(55.3,60.2)$ \\
\hline \multicolumn{6}{|l|}{ Race or Hispanic origin } \\
\hline Non-Hispanic white & 307 & $73.6(66.7,80.6)$ & 0.00 & 1,720 & $61.9(59.7,64.2)$ \\
\hline \multicolumn{6}{|l|}{ Insurance status, current } \\
\hline Any private, including military & 152 & $40.2(32.4,47.9)$ & 0.00 & 1,654 & $63.5(61.0,65.9)$ \\
\hline Medicaid & 191 & $35.3(30.4,40.2)$ & 0.00 & 755 & $18.8(16.9,20.7)$ \\
\hline Other insurance & 30 & $9.0(4.9,13.1)$ & 0.05 & 152 & $4.6(3.6,5.7)$ \\
\hline No insurance & 73 & $15.6(10.7,20.4)$ & 0.30 & 394 & $13.1(11.3,15.0)$ \\
\hline Self-reported fair or poor health & 119 & $29.7(24.1,35.4)$ & 0.00 & 358 & $12.0(10.2,13.8)$ \\
\hline \multicolumn{6}{|l|}{ Mental health, past $12 \mathrm{mo}^{\mathrm{e}}$} \\
\hline Suicidal thoughts and behavior & 90 & $20.1(15.4,24.8)$ & 0.00 & 368 & $10.6(9.2,11.9)$ \\
\hline Major depressive episode & 115 & $25.1(19.7,30.4)$ & 0.00 & 528 & $16.4(14.5,18.4)$ \\
\hline Any mental illness & 279 & $61.9(55.9,67.9)$ & 0.00 & 1,279 & $40.3(37.9,42.6)$ \\
\hline Serious mental illness & 106 & $23.5(19.0,28.0)$ & 0.00 & 420 & $13.2(11.6,14.7)$ \\
\hline \multicolumn{6}{|l|}{ SUDs, past $12 \mathrm{mo}$} \\
\hline Alcohol use disorder & 107 & $22.4(17.3,27.6)$ & 0.00 & 2,440 & $85.7(83.9,87.6)$ \\
\hline Marijuana & 54 & $12.8(8.4,17.2)$ & 0.82 & 472 & $13.3(11.7,15.0)$ \\
\hline Cocaine, including crack & 32 & $6.0(3.3,8.7)$ & 0.04 & 80 & $2.8(1.9,3.7)$ \\
\hline Methamphetamines & 44 & $9.2(5.4,13.0)$ & 0.00 & 126 & $3.4(2.6,4.2)$ \\
\hline Tranquilizers & 50 & $9.8(6.4,13.1)$ & 0.00 & 58 & $1.6(1.0,2.2)$ \\
\hline Other ${ }^{f}$ & 44 & $7.7(4.8,10.7)$ & 0.00 & 82 & $2.4(1.7,3.1)$ \\
\hline Sample size & 446 & & & 2,955 & \\
\hline Rate among parents living with their children & 446 & $0.9(0.8,1.0)$ & 0.00 & 2,955 & $5.9(5.6,6.1)$ \\
\hline \multicolumn{6}{|c|}{ NSDUH = National Survey of Drug Use and Health; OUD = opioid use disorder; Ref = reference; SUD = substance use disorder. } \\
\hline \multicolumn{6}{|c|}{ a Defined as any parent living with a child aged <18 years in the household; sample size 44,464 for 2015-2017. } \\
\hline \multicolumn{6}{|c|}{${ }^{b}$ Estimates are derived from the pooled 2015-2017 NSDUH and adhere to NSDUH requirements for estimation and suppression. ${ }^{9}$} \\
\hline \multirow{2}{*}{\multicolumn{6}{|c|}{$\begin{array}{l}\text { 'Two-sided } t \text { test used to compare difference in means between parents with OUD living with their children and parents with another SUD but not OUD living with } \\
\text { their children. } \\
\text { d NSDUH computes this measure by using each sample person's age, family size, number of children in the household, and family income, including any imputed } \\
\text { income. Because the income questions ask about total family income in } \$ 10,000 \text { increments, the computation assumes the midpoint of the category. }\end{array}$}} \\
\hline & & & & & \\
\hline \multicolumn{6}{|c|}{$\begin{array}{l}\text { "Mental illnesses are defined as a diagnosable mental, behavioral, or emotional disorder, other than a developmental or substance use disorder, assessed by the Men- } \\
\text { tal Health Surveillance Study Structured Clinical Interview for the Diagnostic and Statistical Manual of Mental Disorders-Fourth Edition-Research Version-Axis I Disorders, } \\
\text { which is based on the 4th edition of the Diagnostic and Statistical Manual of Mental Disorders. These mental illness estimates are not direct measures of diagnostic status. } \\
\text { Serious mental illness is defined as mental illness that results in serious functional impairment, which substantially interferes with or limits } \geq 1 \text { major life activities. For } \\
\text { details on the methods, see Section D of the } 2016 \text { NSDUH: Methodological Summary and Definitions. }{ }^{9}\end{array}$} \\
\hline${ }^{f}$ Includes use disorders for sedatives, inhalants, prescr & llants, a & hallucinogens. & & & \\
\hline
\end{tabular}


Table 2. Mean Receiving Drug or Alcohol Use Treatment in a Specialty Facility or Private Doctor's Office $^{\mathrm{a}}$ in the Last 12 Months Among Parents Living With Their Children ${ }^{\mathrm{b}}$ by Past 12 Months OuD or Other SUD Status, 2015-2017

\begin{tabular}{|c|c|c|c|c|c|}
\hline & \multicolumn{2}{|c|}{ OUD $(n=446)$} & \multirow{2}{*}{$\begin{array}{l}P \text { Value for } \\
\text { Difference }^{d}\end{array}$} & \multicolumn{2}{|c|}{$\begin{array}{l}\text { SUDs Except OUD } \\
(n=2,955) \text { [Ref] }\end{array}$} \\
\hline & n & $\%(95 \% \mathrm{Cl})$ & & $\mathbf{n}$ & $\%(95 \% \mathrm{Cl})$ \\
\hline $\begin{array}{l}\text { Treatment for illicit drug or alcohol use at a spe- } \\
\text { cialty facility or private doctor's office }\end{array}$ & 133 & $28.0(21.6,34.3)$ & 0.00 & 184 & $5.6(4.7,6.5)$ \\
\hline $\begin{array}{l}\text { Treatment for illicit drug use at a specialty facility } \\
\text { or private doctor's office }\end{array}$ & 121 & $25.9(19.7,32.1)$ & 0.00 & 98 & $2.9(2.3,3.6)$ \\
\hline $\begin{array}{l}\text { Treatment for alcohol use at a specialty facility or } \\
\text { private doctor's office }\end{array}$ & 35 & $5.9(3.4,8.5)$ & 0.14 & 124 & $4.0(3.1,4.9)$ \\
\hline Any treatment for mental health & 187 & $42.2(34.9,49.5)$ & 0.00 & 753 & $26.0(23.9,28.2)$ \\
\hline \multicolumn{6}{|c|}{$\begin{array}{l}\text { a Including hospital inpatient setting, rehabilitation inpatient setting, rehabilitation outpatient clinic, outpatient mental health center, or private doctor's office. } \\
\text { b Defined as any parent living with a child aged < } 18 \text { years in the household. } \\
\text { 'Estimates are derived from the pooled } 2015-2017 \text { NSDUH and adhere to NSDUH requirements for estimation and suppression. }{ }^{9} \\
\text { d Two-sided } t \text { test used to compare difference in means between parents with OUD living with their children and parents with another SUD but not OUD living with } \\
\text { their children. }\end{array}$} \\
\hline
\end{tabular}

as buprenorphine treatment for those with OUD or extended-release injectable naltrexone for those with alcohol use disorder can be provided in an officebased primary care setting. ${ }^{23}$ The use of standardized patient placement and provider referral tools can help primary care providers ensure that patients who initiate SUD treatment do so in the appropriate care setting (which in some cases may not be the primary care setting) with a high-quality care provider offering the appropriate levels of care and services and accepting new patients. ${ }^{24}$

Raising treatment initiation rates among parents with an SUD in primary care settings may require addressing a range of capacity and infrastructure issues, related to the low availability of evidence-based SUD treatment programs in the community ${ }^{25,26}$ and of family-centered services for parents with OUD and other SUDs. ${ }^{27}$ Many primary care providers do not have the resources and tools to enable them to refer and link people to supportive services that could facilitate treatment initiation and recovery, such as housing, legal assistance, food assistance, and other services related to social determinants of health. ${ }^{28}$ Increasing the share of primary care providers who have waivers from the Drug Enforcement Administration to prescribe buprenorphine for OUD (estimated to be just $3.0 \%$ of primary care physicians in 2012 $)^{29}$ and addressing deficits in clinician education about SUDs and associated treatment ${ }^{30}$ and institutional and financial barriers for providing treatment, including MAT, could also help reduce OUD and SUD treatment gaps among parents. ${ }^{31}$ In addition, treatment initiation can be impeded by lack of insurance coverage and by insurance-related barriers such as prior authorization and cost sharing. ${ }^{32}$ Addressing these issues could increase the share of parents with OUD and other SUDs who are receiving evidence-based treatment, which in turn could improve the health and functioning of parents and their children, protect child welfare, and preserve or reunify families.

A key limitation of our study is that NSDUH data are self-reported and thus subject to recall and social desirability biases, and the sample excludes some populations likely to have high rates of SUDs, such as populations experiencing homelessness or incarceration. ${ }^{11}$ These factors tend to bias downwards the rates of SUDs, with a recent analysis showing the prevalence of OUD in Massachusetts was nearly 4 times higher than the NSDUH prevalence estimates, ${ }^{10}$ although national estimates of the extent or nature of underreporting among parents in NSDUH are not available. Thus, our findings, which suggest substantial unmet needs for OUD and SUD treatment among parents, likely understate the extent of the problem. Despite the limitations of the data, they do offer important, up-to-date information that capitalizes on the strengths of the NSDUH, which is the only survey large enough to support nationally representative estimates and comparisons of parental OUD and other SUDs by sociodemographic characteristics and receipt of treatment.

To read or post commentaries in response to this article, see it online at http://www.AnnFamMed.org/content/17/3/207.

Key words: opioid use disorder; substance use disorder; treatment receipt; substance use treatment; parents

Submitted August 23, 2018; submitted, revised, February 8, 2019; accepted March 6, 2019.

Funding support: The David and Lucile Packard Foundation, Grant Number: 2017-66003 
Acknowledgments: The authors acknowledge the funding support of The David and Lucile Packard Foundation and Dr Doug Wissoker, Dr Stephen Zuckerman, Dr Brendan Saloner, and 3 anonymous reviewers for their insight and expertise.

\section{References}

1. Han B, Compton WM, Jones CM, Cai R. Nonmedical prescription opioid use and use disorders among adults aged 18 through 64 years in the United States, 2003-2013. JAMA. 2015;314(14):1468-1478.

2. Bailey JE, Campagna E, Dart RC; RADARS System Poison Center Investigators. The underrecognized toll of prescription opioid abuse on young children. Ann Emerg Med. 2009;53(4):419-424.

3. Peisch VD, Sullivan A, Breslend NL, et al. Parental opioid abuse: a review of child outcomes, parenting, and parenting interventions. J Child Fam Stud. 2018;27(7):2082-2099.

4. Peleg-Oren N, Teichman M. Young children of parents with substance use disorders (SUD): a review of the literature and implications for social work practice. J Soc Work Pract Addict. 2006;6(1-2):49-61.

5. Quast T, Storch EA, Yampolskaya S. Opioid prescription rates and child removals: evidence from Florida. Health Aff (Millwood). 2018; 37(1):134-139.

6. Wilens TE, Biederman J, Bredin E, et al. A family study of the highrisk children of opioid- and alcohol-dependent parents. Am J Addict. 2002;11(1):41-51.

7. Saloner B, Karthikeyan S. Changes in substance abuse treatment use among individuals with opioid use disorders in the United States, 2004-2013. JAMA. 2015;314(14):1515-1517.

8. Lipari RN, Van Horn SL. Children living with parents who have a substance use disorder. https://www.samhsa.gov/data/sites/default/ files/report_3223/ShortReport-3223.html. Published Aug 24, 2017. Accessed Dec 10, 2018.

9. SAMHSA. National Survey on Drug Use and Health (NSDUH) 2017 methodological summary and definitions. https://www.samhsa.gov/ data/report/2017-methodological-summary-and-definitions. Published Sep 2018. Accessed Dec 11, 2018.

10. Barocas JA, White LF, Wang J, et al. Estimated prevalence of opioid use disorder in Massachusetts, 2011-2015: a capture-recapture analysis. Am J Public Health. 2018;108(12):1675-1681.

11. Center for Behavioral Health Statistics and Quality. 2016 National Survey of Drug Use and Health: Methodological Summary and Definitions. Rockville, MD: Substance Abuse and Mental Health Services Administration; 2017. https://www.samhsa.gov/data/ sites/default/files/NSDUH-MethodSummDefs-2016/NSDUHMethodSummDefs-2016.pdf.

12. Curry SJ, Krist AH, Owens DK, et al; US Preventive Services Task Force. Screening and behavioral counseling interventions to reduce unhealthy alcohol use in adolescents and adults: US Preventive Services Task Force recommendation statement. JAMA. 2018;320(18): 1899-1909.

13. US Surgeon General. Facing Addiction in America: The Surgeon General's Report on Alcohol, Drugs, and Health. Washington, DC: US Department of Health and Human Services, Office of the Surgeon General; 2016. http://archive.hshsl.umaryland.edu/handle/10713/6519. Published Nov 2016. Accessed Jun 15, 2017.

14. SAMHSA. SBIRT: Screening, Brief Intervention, and Referral to Treatment. https://www.integration.samhsa.gov/clinical-practice/ sbirt. Published 2011. Accessed Feb 6, 2019

15. National Institute on Drug Abuse. Screening for drug use in general medical settings: a resource guide for providers. https://www. drugabuse.gov/sites/default/files/resource_guide.pdf. Published 2012.

16. Centers for Disease Control and Prevention. Summary health statistics tables: National Health Interview Survey. https://www.cdc.gov/ nchs/nhis/shs/tables.htm. Published 2018. Accessed Aug 22, 2018.
17. Siu AL, Bibbins-Domingo K, Grossman DC, et al; US Preventive Services Task Force (USPSTF). Screening for depression in adults: US Preventive Services Task Force recommendation statement. JAMA. 2016;315(4):380-387.

18. SAMHSA. The role of adverse childhood experiences in substance misuse and related behavioral health problems. https://www. samhsa.gov/capt/sites/default/files/resources/aces-behavioral-healthproblems.pdf. Updated Jun 2018.

19. Dube SR, Felitti VJ, Dong M, Chapman DP, Giles WH, Anda RF. Childhood abuse, neglect, and household dysfunction and the risk of illicit drug use: the Adverse Childhood Experiences Study. Pediatrics. 2003;111(3):564-572.

20. Ober AJ, Watkins KE, McCullough CM, Setodji CM, Osilla K, Hunter SB. Patient predictors of substance use disorder treatment initiation in primary care. J Subst Abuse Treat. 2018;90:64-72.

21. Friedrichs A, Spies M, Härter M, Buchholz A. Patient preferences and shared decision making in the treatment of substance use disorders: a systematic review of the literature. PLoS One. 2016;11(1): e0145817.

22. The National Council for Behavioral Health. Implementing care for alcohol $\&$ other drug use in medical settings. https://www. thenationalcouncil.org/wp-content/uploads/2018/03/021518_NCBH_ ASPTReport-FINAL.pdf. Published Feb 2018. Accessed Feb 6, 2019.

23. SAMHSA. Medication-assisted treatment (MAT). https://www. samhsa.gov/medication-assisted-treatment. Published 2018. Accessed Dec 21, 2018

24. Pew Charitable Trusts. Substance use disorder treatment policy recommendations for the state of Wisconsin: submitted to the Governor's Task Force on Opioid Abuse. http://legis.wisconsin.gov/ assembly/hope/media/1161/wisconsin-final-report-final.pdf. Published Jul 2018.

25. Bouchery E, Dey J. Substance use disorder workforce issue brief. U.S. Department of Health and Human Services, Office of the Assistant Secretary for Planning and Evaluation. https://aspe.hhs.gov/ system/files/pdf/259346/ExamSUDib.pdf. Published Jun 1, 2018.

26. Jones CM, Campopiano M, Baldwin G, McCance-Katz E. National and state treatment need and capacity for opioid agonist medication-assisted treatment. Am J Public Health. 2015;105(8): e55-e63.

27. Dallas RM, Icenhower K, Kaltenbach K, et al. Perspectives on family-centered care for pregnant and postpartum women: broadening the scope of addiction treatment and recovery. Addiction Technology Transfer Center (ATTC) Network. http://attcppwtools. org/PPW-Monograph-4-Web.pdf. Published 2017. Accessed Dec 21, 2018.

28. Crumley D, Lloyd J, Pucciarello M, Stapelfeld B. Addressing social determinants of health via Medicaid managed care contracts and section 1115 demonstrations. Center for Health Care Strategies. https://www.chcs.org/media/Addressing-SDOH-Medicaid-Contracts1115-Demonstrations-121118.pdf. Published Dec 2018. Accessed Dec 20, 2018.

29. Rosenblatt RA, Andrilla CHA, Catlin M, Larson EH. Geographic and specialty distribution of US physicians trained to treat opioid use disorder. Ann Fam Med. 2015;13(1):23-26.

30. Yarborough BJH, Chi FW, Green CA, et al. Patient and system characteristics associated with performance on the HEDIS measures of alcohol and other drug treatment initiation and engagement. J Addict Med. 2018;12(4):278-286.

31. Jones CM, McCance-Katz EF. Characteristics and prescribing practices of clinicians recently waivered to prescribe buprenorphine for the treatment of opioid use disorder. Addiction. 2019;114(3): 471-482.

32. Sharma A, Kelly SM, Mitchell SG, Gryczynski J, O'Grady KE, Schwartz RP. Update on barriers to pharmacotherapy for opioid use disorders. Curr Psychiatry Rep. 2017;19(6):35. 